\title{
Bioequivalence: The Regulatory Career of a Pharmaceutical Concept
}

\section{Citation}

Carpenter, Daniel, and Dominique A. Tobbell. 2011. “Bioequivalence: The Regulatory Career of a Pharmaceutical Concept." Bulletin of the History of Medicine 85 (1): 93-131. doi:10.1353/ bhm.2011.0024.

\section{Published Version}

doi:10.1353/bhm.2011.0024

\section{Permanent link}

http://nrs.harvard.edu/urn-3:HUL.InstRepos:34257933

\section{Terms of Use}

This article was downloaded from Harvard University's DASH repository, and is made available under the terms and conditions applicable to Other Posted Material, as set forth at http:// nrs.harvard.edu/urn-3:HUL.InstRepos:dash.current.terms-of-use\#LAA

\section{Share Your Story}

The Harvard community has made this article openly available.

Please share how this access benefits you. Submit a story.

\section{Accessibility}




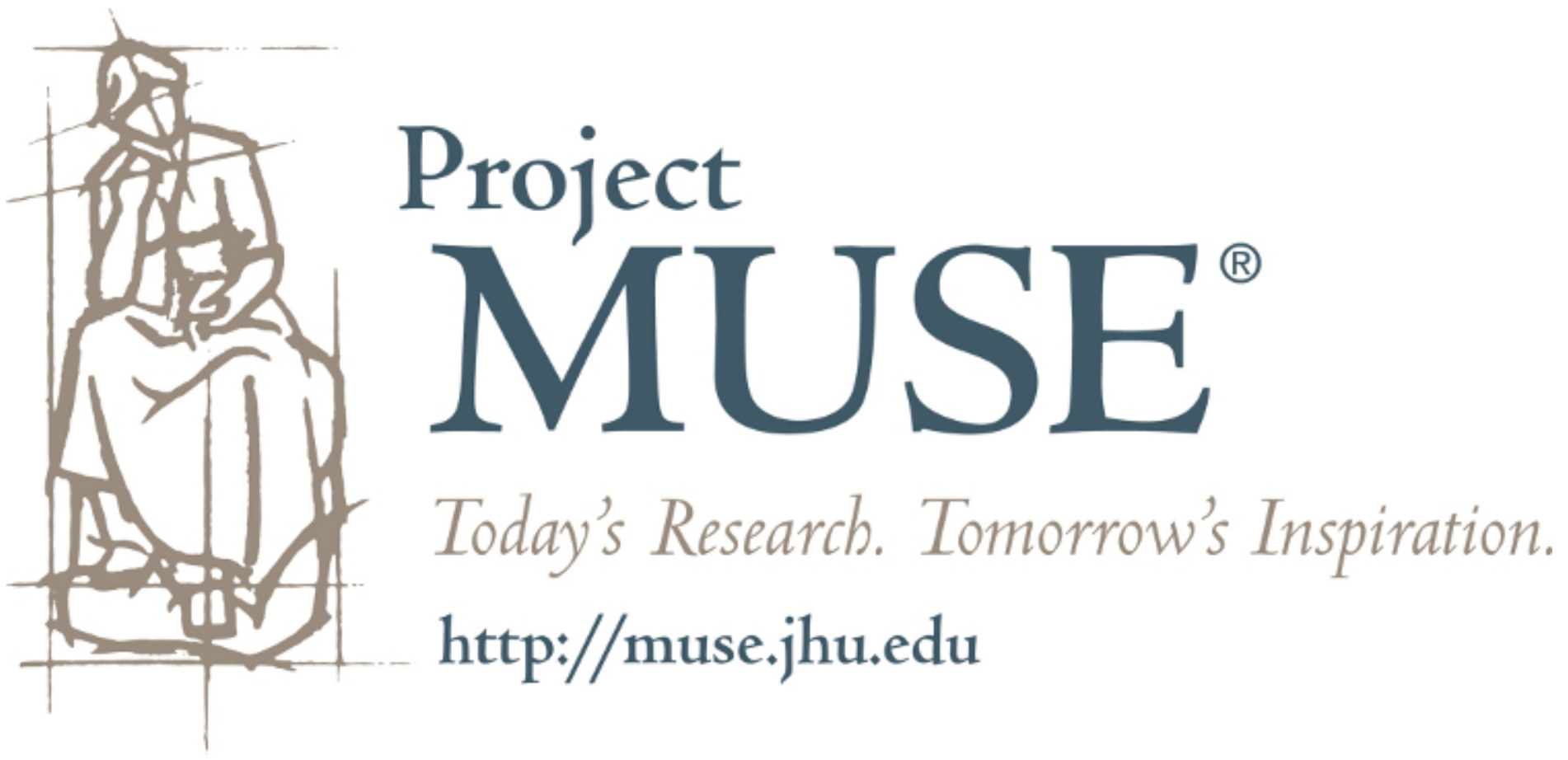




\title{
Bioequivalence: The Regulatory Career of a Pharmaceutical Concept
}

\author{
DANIEL CARPENTER AND DOMINIQUE A. TOBBELL
}

SUMMARY: Generic drugs cannot be marketed without regulatory and clinical demonstration of "bioequivalence." The authors argue that the concept of "bioequivalence" is a joint regulatory and scientific creation, not purely a technical concept, and not purely a legal concept. It developed at the interstices of networks of pharmacologists, regulators, food and drug lawyers, and American and European policy makers interested in "generic" drugs. This article provides a situated perspective on the history of bioequivalence, which emphasizes the shaping role of the state upon scientific processes, networks of regulators and scientists, and the centrality of transnational dynamics in the formation of drug regulatory standards.

KEYWORDS: bioequivalence, drug regulation, generic drugs, regulatory science, Food and Drug Administration

The emergence of a vast generic drug industry in the United States and other nations would not have been possible without fundamental regulatory changes that were struck in the 1984 Hatch-Waxman Legislation. ${ }^{1}$

An earlier version was presented at the Modern Medicines: New Perspectives in Pharmaceutical History conference, American Institute for the History of Pharmacy, Madison, Wisconsin, October 18-19, 2008; the American Political Science Association annual meeting, Toronto, Ontario, panel on Standardization and the State, September 3, 2009; and the Science, Technology and Public Policy Workshop at the University of Michigan, December 7, 2009. For helpful conversations and suggestions, we acknowledge Jerry Avorn, John Carson, Arthur Daemmrich, Jeremy Greene, Rick Hall, Gregory Higby, Peter Barton Hutt, Suzanne White Junod, Desmond King, Shobita Parthasarathy, Marc Stears, Elaine Stroud, John Swann, and Margaret Weir. Rebecca Eisenberg and Harry Marks gave particularly detailed and thoughtful comments, and J. Richard Crout offered valuable advice and historical perspective. All errors and omissions are ours. This essay is dedicated to the memory of Harry Marks. We miss him greatly.

1. In the United States alone, 70 percent of the 3.4 billion prescriptions filled at pharmacies are now completed with generic drugs. 
The Hatch-Waxman law-formally titled the Drug Price Competition and Patent Term Restoration Act (Pub. L. No. 98-417)—created a pathway for the emergence of a vast and legitimized market for generic drugs. The fundamental bargain struck in the legislation was an extension of patent life for "pioneer" molecules (those drugs considered new molecular entities), in exchange for a streamlined and legitimized federal approval process for generic versions of those pioneer molecules. The Hatch-Waxman law, in turn, depended crucially upon the infrastructure for demonstration of "bioequivalence" erected by the Food and Drug Administration (FDA) and cooperating organizations in the preceding two decades. Generic drugs cannot be marketed without regulatory and clinical demonstration of "bioequivalence"-namely, the demonstration that the generic drug not only is chemically identical to the pioneer molecule but also has identical effects within the human patient.

The celebrated bargain of the 1984 law has received healthy narration and study. ${ }^{2}$ Yet the conceptual structure on which that bargain restedthe scientific, economic, and regulatory history of "bioequivalence" and related "bioavailability" concepts as they have developed in the past half century-has not. "Bioequivalence" gives legitimacy and reality to generic drugs. It implies that one pharmaceutical commodity can substitute for another in most (if not all) critical therapeutic respects, and by so doing bioequivalence establishes a framework for market transactions based upon price. It is a joint regulatory and scientific creation, not purely a technical construct, and not purely a legal concept. Bioequivalence developed at the interstices of state, commerce, professional and academic medicine, professional and academic pharmacy, administrative law, and even the politics of federalism. Its development was political in ways that have escaped appreciation by both contemporaries and historians. Bioequivalence pitted generic drug manufacturers against brand-name manufacturers, of course. Just as centrally, however, it pitted different organizational interests against one another-the FDA, U.S. Pharmacopoeia (USP) and the National Formulary (NF), and the American Medical

2. Allan M. Fox and Alan R. Bennett, The Legislative History of the Drug Price Competition and Patent Term Restoration Act of 1984 (Washington, D.C.: Food and Drug Law Institute, 1987); Gerald J. Mossinghoff, "Overview of the Hatch-Waxman Act and Its Impact on the Drug Development Process," Food and Drug Law J. 54 (1999): 187-94; Wendy H. Schacht and John R. Thomas, "Patent Law and Its Application to the Pharmaceutical Industry: An Examination of the Drug Price Competition and Patent Term Restoration Act of 1984 ('The Hatch-Waxman Act')" (RL30756) (Washington, D.C.: Congressional Research Service, 2000); Rebecca S. Eisenberg, "The Shifting Functional Balance of Patents and Drug Regulation," Health Aff. 20, no. 5 (September/October 2001): 119-35. 
Association (AMA) —in an ongoing struggle for control of the conceptual turf at stake, and the policy authority that came with it.

The central action in the saga of bioequivalence was one taken by no single individual, but clearly some agents and organizations advanced the game more than others. The linkage of notions of "equivalence" and "availability" in the late 1960s and early 1970 s both problematized a cozy equilibrium and unraveled a conceptual knot. As drug equivalence was construed less as a problem of applied chemistry and quality control and more as one involving little-understood questions of absorption and pharmacokinetics, a new conceptual space was opened. In this conceptual space-as much regulatory as scientific, and shot through with uncertainty and even palpable fear-proposed standards and definitions could be set forth, some authorities could take the lead in concept framing while other authorities were put on the defensive, and combatants from numerous sides could tie the debate to dozens of related issues of policy and institutions.

The coevolution of bioequivalence and bioavailability made its way from debates over instrumentation to practices of rule making, and finally to legislation. The array of players in this game was vast, and the sphere of combat shifted from professional-medical realms to regulatory and legislative realms and back again. As debates located and relocated, they always retained much of the residue (scientific, political, methodological, administrative) that they acquired. Pharmacological discussions of equivalence echoed the regulatory debates that preceded them, and legislative battles exhibited the filtrated remainder of scientific concept formation.

The emergence of bioequivalence marks a conceptual history, a regulatory history, a history of medicine and of science, and, perhaps most vitally, a history of politics and policy. Important works in the historiography of American governance have shed powerful light on the strength of what was formerly considered a weak American state. ${ }^{3}$ In food and drug regulation, these narratives have focused upon the various explicit and implicit powers of the FDA - its ability to set standards for the development and marketing of new technologies, its ability to quash research and development projects in pharmaceuticals by giving mere hints of its likely disapproval, its position at the interstices of science, medicine, and

3. William J. Novak, "The Myth of the 'Weak' American State," Amer. Hist. Rev. 113 (June 2008): 752-72; Stephen Skowronek, Building a New American State: The Expansion of National Administrative Capacities, 1877-1920 (New York: Cambridge University Press, 1982); Daniel P. Carpenter, The Forging of Bureaucratic Autonomy: Reputations, Networks, and Policy Innovation in Executive Agencies, 1862-1928 (Princeton, N.J.: Princeton University Press, 2001). 
marketplace. Chief among these is what scholars have called "conceptual power" in regulation-the ability of the regulator to secure public aims not through directive or even through agenda setting but through shaping patterns of thought, vocabulary, protocol, and method. ${ }^{4}$ For these reasons, among others, our inquiry combines sources and methods commonly used in the history of medicine and science with concepts and patterns commonly observed in the study of American political development.

As the American nation embarks upon a massive reform of its health care system, the setting of standards in governance of health treatments is also of more than academic interest. A key part of the Patient Protection and Affordable Care Act of 2010 is the creation of a national Patient-Centered Outcome Research Institute for comparative effectiveness research that would systematically (and with considerable public funding) conduct inquiries on which treatments worked better than others for a given disease. Significant funding for this endeavor was included in the American Recovery and Reinvestment Act of 2009, otherwise known as the Obama administration's "stimulus package." In order to be compared, however, treatments must share a common metric of performance against a disease condition, and they must occupy a place of minimal substitutability so as to compose something of both a marketplace and an experimental setting where comparisons are possible. Other scholars working in disciplines as diverse as history, sociology, and political science have also seized upon standard setting and "market making" as modes of regulation different from the interventionist model that has governed American public discourse for the past half century. ${ }^{5}$

4. Sheila Jasanoff, The Fifth Branch: Science Advisers as Policymakers (Cambridge, Mass.: Harvard University Press, 1990); Philip J. Hilts, Protecting America's Health: The FDA, Business and One Hundred Years of Regulation (New York: Knopf, 2003); Arthur Daemmrich, Pharmacopolitics: Drug Regulation in the United States and Germany (Chapel Hill: University of North Carolina Press, 2004); Daniel Carpenter, Reputation and Power: Organizational Image and Pharmaceutical Regulation at the FDA (Princeton, N.J.: Princeton University Press, 2010).

5. Sally Clarke, Regulation and the Revolution in United States Farm Productivity (New York: Cambridge University Press, 1994); Christian Bonah, Christophe Masutti, Anne Rasmussen, and Jonathan Simon, eds., Standards in Pharmaceutical History: Harmonizing 20th Century Drugs (Paris: Editions Glyphe, 2010); Ana Romero, Christoph Gradmann, and Maria Santemases, eds., "Circulation of Antibiotics: Journeys of Drug Standards, 1930-1970" (preprint 1, European Science Foundation Networking Program DRUGS, May 2010); Jeremy Greene, "What's in a Name? Generics and the Persistence of the Pharmaceutical Brand in American Medicine," J. Hist. Med. Allied Sci. (forthcoming). 


\section{Contests over Therapeutic Equivalence, 1950s and 1960s}

The atmosphere of contention in which debates about equivalence emerged was the early Cold War politics of commodity price inflation, aversion to "big" business and monopoly, and the brightening glow of congressional theater. None of these were entirely new forces in American political economy, but their combination was new. At no previous time could a sitting senator such as Estes Kefauver (D-TN) simultaneously tap the expanse of the television medium in the United States, the powers of a chairmanship of a Senate subcommittee, and the particular antitrust currents of the 1950 s that had been energized by inflation and by economic citizenship. Kefauver's hearings took square aim at the "markup" pricing of brand-name drug tablets, and he proposed federal legislation that mandated "generic switching" in physician prescribing, the prominent listing of generic names along with trade names on drug labels and advertisements, and limitations on pharmaceutical patents. ${ }^{6}$

Questions about equivalence were thus caught up in larger battles about drug nomenclature and the incentives facing general practitioners and other physician prescribers. The Kefauver proposals reinvigorated earlier arguments between pharmacists' associations and brand-name manufacturers about whether drugs should be called by their brand names or their trade names and whether physicians should be discouraged from prescribing brand names when generic alternatives were available. For their part, physicians' associations tended to side with the brand-name manufacturers. The American Academy of General Practice in 1954 openly disavowed any action to discourage the use of trademark names in prescription writing.

Brand-name manufacturers used many strategies against Kefauver's plans, of course, but before, during, and after the Tennessee senator's hearings they and their political organs tried to undermine the notion that generic drugs were truly equivalent to brand-name drugs. In a pamphlet titled "Misconceptions about So-Called 'Generic Equivalent' Drugs" (1961), the pharmaceutical industry's policy research organization, the National Pharmaceutical Council (NPC) questioned the "confident assertions" made by proponents of price regulation and mandated generic substitution "that the cost of medicines could be greatly reduced if 
physicians would, or were compelled to, prescribe drugs by their generic or nonproprietary names rather than the brand names of manufacturers. This concept," the pamphlet continued,

assumes that all generic-name drugs are identical; that all have identical therapeutic actions in the patient. . . . Are these assumptions true? Is it really desirable or much-less expensive, for you or a member of your family to take a generic-name drug, made by a manufacturer unknown to your physician or to you, when the course of a minor or serious illness depends upon the complex composition and actual action in the body of the preparation you take? ${ }^{7}$

The pamphlet offered a list of cases in which a "subtle and sometimes hazardous range of differences" between the brand-name molecule and the purported generic equivalent had been revealed. Analyses of sustained-release amphetamine preparations showed that commonly available tablets delivered as little as one-third of the required dose; studies of larger generic tablets of Eli Lilly's anticoagulant dicumarol showed that larger dosage tablets simply used a higher quantity of the inert base as opposed to a larger portion of the active ingredient; a fifty milligram pill was therapeutically equivalent to a twenty-five milligram pill. Generic tablets for the antituberculosis medicine p-aminosalycylic acid were coated with shellac, whose chemical structure destabilized from aging; observed blood levels of the acid after intake were less than considered therapeutically effective. $^{8}$

For two generations, the question of therapeutic equivalence had largely been addressed through analyses of chemical equivalence. In the 1950 s and early 1960s, among the sparse tools available to pharmacologists to address these questions were dissolution studies and urinalysis ("excretion studies"). In the main, blood plasma analysis was considered too expensive to be conducted routinely of most tablet drugs, and plasma measurements for most drugs were not developed. Combined with the FDA's well-honed good manufacturing practices (GMPs) - a list of production control standards that quickly became an industry-wide template in the late $1940 \mathrm{~s}$ and $1950 \mathrm{~s}$ - chemical equivalence tests rounded out the complement of tools available to monitors in the USP and regulators at the FDA. ${ }^{9}$ In the customary generic drug application, a "paper NDA" or,

7. National Pharmaceutical Council, "Misconceptions about So-Called 'Generic Equivalent' Drugs" (New York: National Pharmaceutical Council, 1961), copy in Records of the U.S. Pharmacopoeial Convention (B82, F11), Wisconsin State History Society, Madison, Wis. (hereafter, USP Records).

8. Ibid., 5-6.

9. John P. Swann, "The 1941 Sulfathiazole Disaster and the Birth of Good Manufacturing Practices," PDA J. Pharmaceut. Sci. Technol. 53, no. 3 (May 1999): 148-53. 
after 1969, an abbreviated new drug application (ANDA) would combine manufacturing controls data with chemical equivalence demonstrations. The paper NDA attached these to aggregated "paper" evidence (from the published medical literature and from the FDA's review documents) of the molecule's effectiveness. Yet even a successful paper NDA or ANDA left the brand-name manufacturer in the position of being able to argue that only the brand-name product had been the subject of direct clinical investigations by medical authorities and by the FDA.

In this environment of weak knowledge and uncertainty, the aim of the brand-name manufacturers' political campaign against generic drugs was clear. Attacking the plausibility of generic substitution required an assault upon the equivalence of generic drugs as well as institutions that served to bolster equivalence claims. Hence part of the NPC's criticisms was aimed at the USP, which since the 1906 Pure Food and Drug Act had certified drugs for their strength, purity, and potency. Citing the Kefauver hearings testimony of FDA commissioner George Larrick and even USP director Lloyd Miller, the council's pamphlet declared that

the mere presence of "U.S.P." on a label is in itself no assurance that contents meet official standards. The product may not even comply with minimum standard requirements. The U.S.P. may also permit differences of ingredients added in formulating a product. These may exert differences in therapeutic response. ${ }^{10}$

Neither the thalidomide episode nor the Kefauver-Harris Amendments nor the Investigational New Drug (IND) regulations of 1963 broke open this stalemate. The patent provisions of the Kefauver bill did not pass, and mandatory generic prescribing also failed to become law. In one important domain of contestation, the brand-name drug makers lost. The FDA was charged with creating a new system of drug nomenclature that would allow for easier comparisons among molecules. Yet the amendments did not create a system for the official establishment of "therapeutic equivalence." In many respects, considering the vast policy opening created by the thalidomide scare and Frances Kelsey's public triumph of the summer of 1962, the industry trade association, the Pharmaceutical Manufacturers Association (PMA), and the NPC had dodged a bullet.

It comes as little surprise, then, that in the years immediately following the 1962 amendments, brand-name manufacturers continued their attack on the plausibility of generic equivalence. In a June 1965 address to the Hillsboro County Medical Association in Tampa, Florida, A. E. Slesser of Smith, Kline \& French Laboratories hammered away at 
the "myth of generic "equivalency." Slesser pointed to the oft-repeated slogan of brand-name manufacturers-chemical equivalence did not imply "therapeutic equivalence," and the identity of a "drug product" (a dosage form) did not map cleanly into the identity of the "drug" per se as a therapeutic agent. In the years after 1962, Slesser and other industry spokesmen skillfully reappropriated the language and terms of the Kefauver-Harris Amendments and of pharmacological reformers of an earlier generation, reminding their audiences that the core question in thinking about generic substitution was not cost but "efficacy." "There is only one way of assuring the therapeutic efficacy of a drug product," Slesser reminded his Tampa listeners, "and that is by properly designed and controlled clinical tests." 11

The increasingly regulated nature of brand-name companies' endeavors, then, conferred what their officials saw as a saleable advantage in reputation. Neither the generic firms themselves nor the USP could, in this rendering, approach the exhaustive processes governed by the FDA and regularly executed by the "reputable" brand-name manufacturer. In making this argument, Slesser depicted brand-name drug synthesis and manufacture as an essentially bureaucratic enterprise:

The reputable manufacturer (and the FDA!) recognizes the indispensability of in-process controls in assuring drug quality and assuring validity of sampling and test results throughout the manufacture of each batch. His in-process controls consist of such things as records and reports giving results of required tests and inspections. Records, such as the results of tests throughout the manufacture of each batch as it is being compressed; control chart records of the fill accuracy of capsules as the batch is being encapsulated; signatures of operators and supervisors attesting to the double and triple weight and identity checks that have been made on each component in the compounding of the batch; signatures of operators and supervisors denoting that the correct working directions were used in compounding the batch; yield checks; analytical reports, etc. ${ }^{12}$

The kinds of assessments-“double and triple weight and quality checks"that allowed for faithful attributions of therapeutic equivalence were possible, Slesser implied, only in the corporately organized pharmaceutical companies that developed, synthesized, and packaged molecules. What larger pharmaceutical companies offered was not merely a more robust

11. A. E. Slesser (assistant technical director, SK\&F Labs), "The Myth of Drug Product 'Equivalency'” (address, Hillsboro County Medical Association meeting, June 1, 1965), copy in USP Records.

12. Ibid., 9-10. 
development enterprise but a built-in system of redundancies and evaluation points that, together with brand-name dynamics, generated a more stable end product.

\section{Congressional Critique: The Chemical "Inequivalence" of Generic Drugs}

In spite of Slesser's assertions, Congress was skeptical of such claims of brand-name superiority. Senator Gaylord Nelson (D-WI) had taken over the prescription drug reform mantle following Kefauver's death, and it was as chair of the Senate Select Committee on Small Business that Nelson began his own investigation into the American pharmaceutical industry in 1967. Like Kefauver, Nelson regarded mandatory generic prescribing as the solution to rising prescription and health care costs, and he joined with others in Congress (Joseph Montoya and Russell Long, in particular) and in state legislatures to push for the use of generic drugs for all welfare patients and to secure prescription drug benefits for seniors under Medicare..$^{13}$

To defend against congressional calls for mandatory generic prescribing, the brand-name manufacturers, led by the PMA, did as they had since passage of the 1962 Drug Amendments: they attacked the concept of generic equivalence. This meant the mobilization of a vigorous public relations and political campaign aimed at undermining the notion that generic drugs were truly equivalent to their brand-name counterparts. In addition to the NPC's "Misconceptions about So-Called 'Generic Equivalent' Drugs," the PMA circulated among physicians' offices and pharmacies and congressional members and staffers two other pamphlets that warned of the dangers of making generic prescribing mandatory, "Compulsory Generic Prescribing-A Peril to the Health Care System" and "Drugs Anonymous?" The latter warned that such action "could and probably would bring about deterioration in the quality of medical care - through the wide sale of substandard products-by discouraging the struggle for excellence which has marked the astounding progress in the pharmaceutical field-and by impeding drug research on which future progress depends." 14

13. Dominique A. Tobbell, "Pharmaceutical Networks: The Political Economy of Drug Development in the United States, 1945-1980" (Ph.D. diss., University of Pennsylvania, 2008), esp. 191-232.

14. Pharmaceutical Manufacturers Association (PMA), "Drugs Anonymous?" (Washington, D.C.: PMA, 1967), National Museum of American History, Parke-Davis Collection, box 1964, quotation from p. 15. For information on "Compulsory Generic Prescribing-A Peril to the Health Care System," see Senator Gaylord Nelson, "Drug Quality Standards," Cong. Rec. 113, no. 5 (1967): 5630-31. 
On the congressional stage, representatives from brand-name manufacturers testified in front of Nelson's subcommittee as to the superiority of their products compared to the generic versions produced by small, nonresearch-based companies. In 1967 the PMA's president, C. Joseph Stetler, cited a recent Parke-Davis study that had compared the equivalence of its own brand of chloramphenicol (Chloromycetin) and several generic versions of the drug and found that some of the generic drugs were absorbed into the blood stream of human volunteers at rates remarkably different from the Parke-Davis brand. Subsequently, the FDA withdrew nine of the generic chloramphenicol drugs from the market. ${ }^{15}$ Here, Stetler argued, was clear evidence that "[a]lthough two products may contain, or are supposed to contain, the same amount of the same active ingredient, this provides no assurance that both products will produce the same clinical effect in any particular patient." ${ }^{16}$ Because the inactive ingredients that made up a drug product influenced the absorption and efficacy of the drug's active ingredient, Stetler's point made clear that containing the same amount of active ingredient was not enough to guarantee the therapeutic equivalence of a generic drug. Stetler's argument thus extended brand-name manufacturers' opposition to generic equivalence beyond the assertion that generic firms lacked sufficient quality control procedures. There was a modest rhetorical shift here, one pointing not to new standards but to doubts about what equivalence meant and how to measure it. Brand-name companies sought to exploit this uncertainty, which created a partial but effective therapeutic rationale against generic prescribing.

In the absence of comparative data, brand-name manufacturers held up the regulatory process as a guarantee of brand-name superiority. Despite the lack of comparative clinical data to support his point, Ciba's president, Charles T. Silloway, argued that Ciba's brand of reserpine (Serpasil) was much better than the reserpine manufactured by the generic firm, American Pharmaceutical Corp, “[b] ecause ours consistently meets the standards of the USP and exceeds them, and because our product has

15. On October 19, 1967, the FDA withdrew certification of generic versions of chloramphenicol produced by the firms McKesson Laboratories, Continental Laboratories, the Pharmusa Corporation, the Davis-Edwards Pharmacal Corporation, Rachelle Laboratories, and Westward, Inc. after laboratory tests showed Parke-Davis's Chloromycetin brand entered the bloodstream faster than its generic competitors. "FDA Limits Drug to One Company," New York Times, December 22, 1967, 29; FDC Reports, November 6, 1967, T\&G 7.

16. "Statement of C. Joseph Stetler, President, PMA," Competitive Problems in the Drug Industry, Hearings before the Senate Select Committee on Small Business; Monopoly Subcommittee, 1967-1977 (hereafter Nelson Hearings), November 16, 1967, 1367-1400, quotation on 1367. 
been extensively clinically studied. Their product had not been." 17 In the arena of regulatory standards, the brand-name manufacturers had a point: although the 1962 Drug Amendments mandated that all new chemical entities (and therefore brand-name drugs) undergo rigorous clinical evaluation before the FDA could grant marketing approval, generic drugs, named for the very fact that they were not new chemical entities, fell out of the purview of any such requirement and were granted approval merely upon demonstration of their chemical equivalence to their brand-name counterpart. As is discussed below, this two-tiered regulatory process gave scientific credibility to the PMA's critique.

In their effort to undermine Nelson's bid, the PMA had as its ally the AMA. Although the AMA's membership and political legitimacy had dwindled during the previous decade, the physician group was still a formidable force in health care policy. Following passage of Medicaid and Medicare, the AMA leadership criticized any legislative effort-including mandatory generic prescribing - that looked to grant the federal government any further control over medical practice. In an editorial in the $A M A$ News, the physician group argued that physicians prescribed drugs by brand name so that they could be confident in the drugs' quality. Any "[1] egislation that would nullify this knowledge [about quality] by removing the decision-making power from him," the AMA asserted, "clearly is not in the public interest." 18

Despite the PMA's campaign, Nelson was unconvinced by the testimony of representatives from brand-name manufacturers and the AMA. Instead, as he heard repeated testimony from representatives of hospital formulary committees and municipal and state welfare agencies who attested to the success of using generic drugs in their programs, Nelson labeled the brand-name manufacturers' assertions of generic inequivalence as "gobbledygook" and accused them of "broad-scale" propaganda

17. "Statement of Charles T. Silloway, President, Ciba Pharmaceutical Co.," Nelson Hearings, September 14, 1967, 896-922, quotation on 907.

18. AMA, "Generic Prescribing Doesn't Guarantee Lower Drug Costs, Chicago Survey Shows" (news release, May 26, 1967), cited in Milton Silverman and Philip R. Lee, Pills, Profits, and Politics (Berkeley: University of California Press, 1974), 147, 364n16. On AMA opposition to the FDA and on AMA-PMA alliances, see also Harry M. Marks, "Making Risks Visible: The Science \& Politics of Adverse Drug Reactions," in Ways of Regulating: Therapeutic Agents between Plants, Shops and Consulting Rooms, ed. Jean-Paul Gaudillière and Völker Hess (preprint 363, Berlin: Max Planck Institute für Wissenschaftsgeschichte, 2008), 105-22; and Dominique A. Tobbell, "'Eroding the Physician's Control over Therapy': The Post-War Politics of the Prescription," in The American Prescription from the New Deal to the New Millennium, ed. Elizabeth Watkins and Jeremy Greene (Baltimore: Johns Hopkins University Press, forthcoming). 
"with the obvious purpose to destroy public confidence in the official standards and the general quality of drug products." 19 At the root of the issue of generic equivalence, however, lay a very real scientific concern: was chemical equivalence (the current regulatory standards required for generic drug approval) a guarantee of therapeutic equivalence?

\section{The Coevolution of Availability and Equivalence}

The PMA's was a campaign to sow doubt, and that campaign succeeded in part because the doubt was not unreasonable. As early as 1961, academic pharmacists expressed grave misgivings about the tools of their trade as a number of studies raised problems with the concept of therapeutic equivalence. The most significant step in the evolution of regulatory standards came in the regulatory linkage established between the concepts of equivalence and "biological availability." The emergence of generic drug equivalence standards was in large measure the coevolution of "bioavailability" and "bioequivalence" concepts, or in the coevolution of a biological standard and an associated regulatory standard. It is important to state what this transformation was not. It was not the case of a purely "scientific" development driving changes in regulation. Nor was it the case of a "regulatory development" driving science.

The notion of the availability of a therapeutic or nutritional ingredient had been under study among agricultural researchers, nutrition and physiology scholars, food and drug specialists, and others since the 1920s. At the core of these studies was a problem that long bothered observers of animal nutrition but was poorly solved in human pharmacokinetics as of the early 1970s. As two Texas experiment station researchers described their problem in 1948,

[t] he nutritive value of a protein is dependent not only upon its content of essential amino acids but the biological availability of these amino acids as well. Incomplete digestion and absorption of an essential amino acid has the result of altering the effective composition of a food protein. The ultimate synthesis of body protein from the amino acids made available through diges-

19. "Statement of Charles T. Silloway" (n. 17), 908; Gaylord Nelson, "Therapeutic Equivalency of Drugs," Cong. Rec. 115, no. 5 (1969): 6426-28, esp. 6427. Testifying in support of generic prescribing were groups representing senior citizens (e.g., "Statement of James L. Browning," Nelson Hearings, May 15, 1967, 122-27), representatives from hospitals with success using formularies of generic drugs (e.g., "Statement of Dr. Harold F. Newman," Nelson Hearings, May 17, 1967, 219-27), and representatives of municipal and state governments with experience purchasing generic drugs for their hospital and welfare programs (e.g., “Statement of Dr. James G. Haughton,” Nelson Hearings, June 8, 1967, 383-97). 
tion and absorption is dependent on a third factor, namely, the simultaneous appearance in the blood stream of each of the essential amino acids in suitable proportion. ${ }^{20}$

These discussions of "biological availability" floated among disciplinary conversations in nutrition, physiology, and pharmacology for much of the 1940s, 1950s, and 1960s. By the early 1960s, a slate of studies and their clinical and methodological implications began to worry officials at the NF and the USP. The central studies had been conducted by antibiotic researchers, by Scandinavian tuberculosis researchers, and by University of Buffalo academic pharmacist Gerhard Levy and his colleagues. Studies from 1947 onward demonstrated that dicalcium phosphate administered with tetracycline appreciably depressed absorption of the antibiotic. In the 1950 s and early 1960s, other researchers showed that crystalline novobiocin acid was absorbed in ways starkly different from amorphous novobiocin acid and that the diuretic spironolactone differed markedly across dosage forms in its absorption into the blood stream. Studies soon showed varying ranges of activity in commonly used steroids, including prednisone. ${ }^{21}$

A series of studies conducted during the 1950s and early 1960 s by researchers at the Food and Drug Directorate (FDD) of Canada's Department of National Health and Welfare raised concerns about existing pharmacopoeial standards of equivalence, particularly dissolution and disintegration tests. As the FDD researchers noted, while "various disintegration methods and times are specified in pharmacopoeias ... few attempts have been made by the pharmaceutical industry or by regulatory bodies to relate such tests to quantitative measures of the physiological availability of the ingredients of the tablets." The FDD researchers had hoped through their studies of various vitamin and drug products to delineate the relationship between in vitro disintegration times and biological availability (as measured using in vivo urinary excretion studies). Instead they found that for several drug products in vitro disintegration times were an inadequate measure of availability and thus did not guarantee the biological equivalence of the drug products. The FDD researchers also found that sustained-release and delayed-release dosage forms of a number of drug

20. K. A. Kuiken and Carl M. Lyman, "Availability of Amino Acids in Some Foods," J. Nutr. 36 (1948): 359-68, quotation on 359.

21. D. G. Chapman, R. Crisafio, and J. A. Campbell, "The Relation between in Vitro Disintegration Time of Sugar-Coated Tablets and Physiological Availability of Sodium p-Aminosalicylate," J. Amer. Pharmaceut. Assoc. (Sci. Ed.) 45 (1956): 374-78; J. D. Mullins and T. J. Macek, "Some Pharmaceutical Properties of Novobiocin," J. Amer. Pharmaceut. Assoc. (Sci. Ed.) 49 (1960): 245-48; Gerhard Levy, "Availability of Spironolactone Given by Mouth," Lancet (October 6, 1962): 723-24. 
products produced inadequate bioavailability, adding to concerns about the therapeutic equivalence of different dosage forms. ${ }^{22}$

At the National Formulary Committee meeting of September 1961, University of California pharmacist Einar Brochmann-Hansen expressed a commonly shared sense of methodological humility.

Like so many of us who are concerned about drug standards as a means of quality control, I had fallen into the rut of thinking almost entirely in terms of the identity, purity and quantity of active ingredient present in the dosage form; that any brand of the same drug which would meet the official specifications with regard to these and other requirements, would be therapeutically equivalent. Recently, a handful of people in this country and elsewhere have been making a lot of noise telling us that the situation is not nearly as simple as that. ... It is not enough that the active ingredient is of the right identity and purity and is present in the labeled quantity. It must also be available for absorption if the drug is going to show the desired pharmacological effect. ${ }^{23}$

The problem, as Brochmann-Hansen perceived it, lay in the limits of the dissolution test. "Here we come to the crux of the matter: the disintegration time test tells us very little, if anything, about the physiologic availability of the drug." 24

At the USP, director of revision Lloyd C. Miller watched these developments with organizational alarm. The USP was the author of the standards that generic drugs were required to meet, and the organization developed these "reference standards" in consultation with state colleges of pharmacy, a pattern of consultation and collaboration that dated to the nineteenth century. These standards were based upon the physical amount and chemical purity of active ingredients.

In the early 1960s, Miller began to hear from longtime colleagues in his and related disciplines-Dale Friend of Harvard Medical School and

22. D. G. Chapman, L. G. Chatten, and J. A. Campbell, "Physiological Availability of Drugs in Tablets," Can. Med. Assoc. J. 76, no. 2 (1957): 102-6, quotation on 103; A. B. Morrison and J. A. Campbell, "The Relationship between Physiological Availability of Salicylates and Riboflavin and in Vitro Disintegration of Enteric Coated Tablets," J. Amer. Pharmaceut. Assoc. 49, no. 7 (1960): 473-78; A. B. Morrison, C. B. Perusse, and J. A. Campbell, "The Relationship between in Vitro Disintegration Time and in Vivo Release of Vitamins from a Triple-Dose Spaced-Release Preparation," J. Pharmaceut. Sci. 51, no. 7 (1962): 623-26; and Denys Cook, "History of Bioavailability Testing at the Food and Drug Directorate," Revue Canadienne de Biologie 32, supplement (1973): 157-62.

23. Einar Brochmann-Hansen, "Physiological Availability of Drugs in Pharmaceutical Dosage Forms" (presented at the National Formulary Committee meeting, Washington, D.C., September 22, 1961), 1, USP Records.

24. Ibid., 1. 
the Brigham Hospital in Boston and Walter Modell, a clinical pharmacologist at Cornell University Medical College. Friend and Modell expressed concern not only about the problem of therapeutic equivalence but also about what the implications of this issue were for the relevance of the USP. Friend wrote that "sooner or later we certainly are going to have to take some cognizance of the problem of compounding and biological availability." Two weeks earlier Modell had confided to Miller that "the problem of 'pharmacologic' availability of drugs concerns me. It seems to me that little is to be found in the literature at this time about this aspect of new drug preparations. It seems to me also that U.S.P. can deal with it only by broadening the scope of its operations. Let's talk about it." In a subsequent phone conversation, Modell expressed his fear that the bioavailability problem was "different for almost every drug," so much so that the "USP cannot provide standards with its present state of knowledge." 25 And in meetings he attended, Miller began to realize that the legitimacy of the USP determinations was in trouble. In a circular sent around in September 1961, he acknowledged that "it will be clear at once from the reports that a new kind of official standard is needed, i.e., one that may well be too complex to apply to every batch of product. If so, this will represent a most significant departure in approach to drafting drug standards." 26

Nor could the FDA's GMPs assist well with this problem. GMPs could address the problem of quality control—variability from tablet to tablet in chemical composition. Yet the new studies were suggesting that, over the course of the administration of a drug, there was "physiological" or "biological" variance within the individual patient. So too that across different forms of tablet and dosage form, there was striking variance in availability even when the manufacturing controls had been fully satisfied.

Smith, Kline \& French officials held a small conference on "physiologic availability" in 1963 in Philadelphia, and Miller attended the meeting of the "Tablets Committee." Officials from numerous brand-name firms were in attendance-Squibb, Abbott, Parke-Davis, Upjohn—along with Gerhard Levy from the University of Buffalo. From the discussion Miller learned that in the coming decade of control testing, the "[i]nfluence of Govt. will steadily increase.” John Wagner of Upjohn presented data that showed two different dosage forms of the company's star product tolbutamide issued in markedly different blood sugar levels over a twelve-hour

25. Friend to Miller, November 25, 1963; Modell to Miller, November 13, 1963; notes from phone conversation (probably Miller's handwriting), n.d., USP Records.

26. Miller, "Physiological Availability and Homogeneity in U.S.P. Dosage Forms," circular 30, U.S.P. Committee of Revision, September 28, 1961, 108, USP Records. 
time span, and upon sketching the plot of Wagner's data, Miller noted the conclusion that USP and NF standards needed to be "revamped" (see Figure 1). ${ }^{27}$

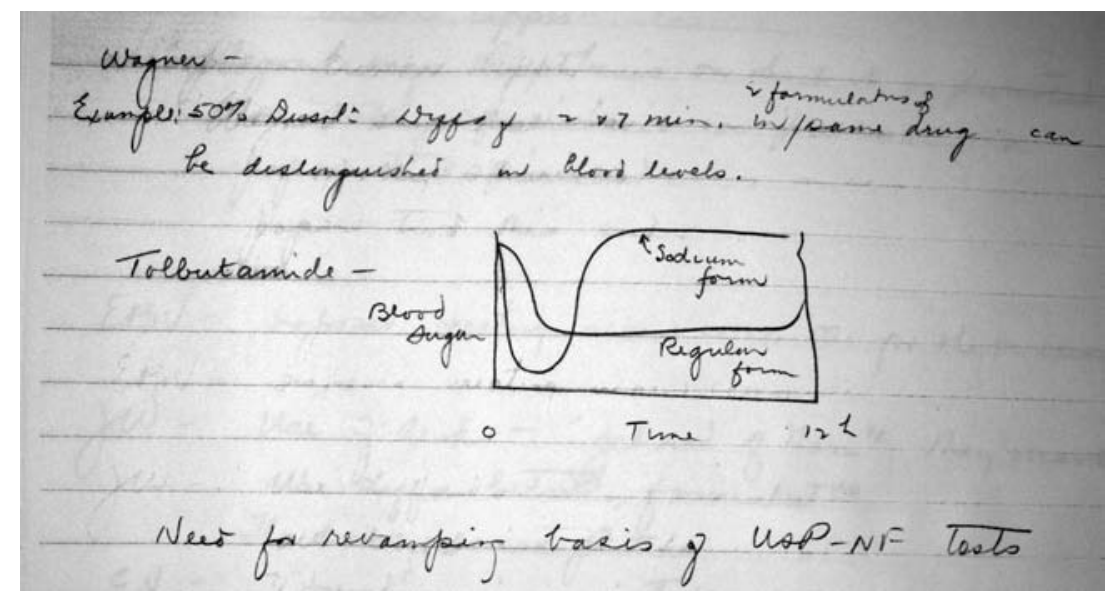

Figure 1. U.S. Pharmacopoeia Revision Director Lloyd Miller's notes on the availability of Tolbutamide, 1963. Reprinted with permission of The United States Pharmacopeial Convention, Rockville, Maryland. Source: Wisconsin State History Society, Madison, Wisconsin.

Wagner's presentation on tolbutamide, combined with Miller's anxious notes on it, marks a turning point in the organizational politics and conceptual structure of the bioequivalence debate. Wagner's imagery presented a powerful challenge to existing standards of equivalence determination-many of them "owned and operated" by the USP. And discussions of physiological availability gestured to the wide gulf between chemical equivalence and therapeutic equivalence, not merely at any one time but also in ways that were dynamic and dose dependent.

\section{DES and the Transformation of New Drug Review}

As the issue of therapeutic equivalence gained legislative traction during the Nelson hearings, a series of advisory bodies-working at the behest of government officials—entered into the debate over generic drugs and their

27. Miller, Notes from "Conf. on Physiological Availability," March 28, 1963, USP Records. Beginning in the late 1960s, Wagner worked with the Bureau of Drugs under a consulting contract. 
substitutability for more expensive molecular therapies. In 1967, the Secretary of Health, Education, and Welfare established a Task Force on Prescription Drugs-composed of government officials, some without medical or scientific training - to determine the feasibility of expanding the Medicare program to include prescription drug coverage. Part of the Task Force's study included an assessment of the benefits of using generic drugs, which in turn included an assessment of the matter of therapeutic equivalence. ${ }^{28}$

As part of its evaluation, the Task Force initiated a program to determine whether any observed differences in biological equivalence (or bioequivalence) could be related to differences in the physical or chemical characteristics of the products (such as particle size, crystal form, and adjuvants used such as fillers, lubricants, binders, coatings, etc.). The Task Force selected twenty-seven drugs (considered to be the most critical) to study in clinical trials. Beginning in late 1967, bioequivalency studies on these products were conducted in human volunteers in FDA laboratories; at Georgetown University, under FDA contract; and at the Public Health Service Hospital in San Francisco. While on-site physicians and researchers conducted the studies, the Task Force oversaw the equivalency trials. The Task Force projected that these clinical trials would be complete and the data on hand by 1971. In the meantime, based on reviews of the current literature on therapeutic equivalence and through assessments of the use of generic drugs in foreign drug programs, in leading American hospitals, in state welfare programs, in Veterans Administration and Public Health Service hospitals, and in American military operations-where few cases of inequivalency with therapeutic consequences had been reported-the Task Force concluded, "[o]n the basis of available evidence, lack of clinical equivalency among chemical equivalents meeting all official standards has been grossly exaggerated as a major hazard to the public health." 29

The Task Force's findings were a boon to Nelson. Yet the matter of therapeutic equivalence was far from resolved. As part of the 1962 Drug Amendments, the FDA was required to review the efficacy of all drugs marketed between 1938 and 1962, some four thousand drugs. Without the resources to conduct the review itself, the FDA contracted the work out to the National Research Council, which oversaw the efficacy review and coordinated the recruitment of thirty advisory panels composed of almost two hundred academic physicians deemed experts in critical areas

28. Office of the Secretary, U.S. Department of Health, Education, and Welfare, "Final Report of the Task Force on Prescription Drugs" (Washington, D.C., 1969), iii.

29. Ibid., 31-34, quotation on 31. For discussion of the Task Force and particularly its oversight of equivalency trials, see Silverman and Lee, Pills, Profits, and Politics (n. 18), 151-62. 
of drug evaluation to perform the evaluations; this came to be called the Drug Efficacy Study (DES) ${ }^{30}$ The DES panels based their evaluations of each drug on published studies, the original new drug application (NDA) and other materials on file with the FDA, the drug's package insert, supplemental material (usually unpublished studies) provided by the manufacturer, and the panel members' experiences using the drug in clinical practice. ${ }^{31}$ The DES completed the evaluations in just three years, after which time the FDA decided, based on the DES's reports, which drugs were to be pulled from the market because they did not have sufficient evidence of efficacy and which drugs required labeling changes to more accurately reflect the DES's findings.

The DES included the evaluation of brand-name and generic drugs and thus directly confronted the matter of the therapeutic equivalence of generic drugs. During the evaluation process, however, the DES panels found that for many of the generic drugs studied, there was no evidence available to show that the generic drugs were in fact therapeutically equivalent to their brand-name counterpart. Rather, all the DES panels could say about a generic drug's efficacy was whether that generic drug was chemically equivalent to a brand-name drug whose efficacy had been determined. ${ }^{32}$

This problem was due to what the Policy Advisory Committee (PAC) of the DES regarded as a double standard in the regulatory process. The manufacturer of a brand-name drug had to apply to the FDA for a supplementary NDA, for any change in formulation, no matter how slight, and in so doing provided to the FDA therapeutic equivalence data for any and all changes. Meanwhile, the manufacturer of a generic drug was required to supply only proof of the drug's chemical equivalence to the alreadyapproved brand-name drug. By "rendering decisions on the efficacy of 'generic' drugs" and "accepting inadequate 'in vitro' tests as adequate evidence of therapeutic equivalency," the PAC believed the DES violated the letter of the 1962 Drug Amendments because without clinical data, "we have no idea of the efficacy in man of many of the generic drugs that

30. Governing Board, National Research Council, minutes of NRC Governing Board meeting, April 24, 1996, appendix 7.2, NAS Archives, Medical Sciences, DRB folder, Committee on Drug Efficacy Review Ad Hoc 1966.

31. Ralph G. Smith, "The Drug Efficacy Study of the NAS-NRC," November 19, 1968, NAS Archives, series 1 DES, DES of NAS-NRC, Smith R G 1968.

32. R. Keith Cannan, "The Drug Efficacy Study of the NAS-NRC: A Talk Given at the Sixth Annual Briefing in Science Council for the Advancement of Science Writing, November 11, 1968," NAS Archives, series 1 DES, Speeches on History and Work of DES by Cannan, Gilman, and Trexler, 1966-68. 
we have declared to be effective." ${ }^{33}$ In light of this, the PAC added an addendum to each drug evaluation submitted by the DES to the FDA:

Drugs of identical chemical composition (so-called generic drugs) formulated and marketed by numerous individual firms under generic or trademarked names have been evaluated for efficacy as a group without consideration of "therapeutic equivalence." In the event that no evidence for pharmacological availability or therapeutic efficacy in man can be presented for any of the drugs in the attached listing, their classifications of effectiveness may need to be modified if future regulations of the FDA require such proof. ${ }^{34}$

Recognizing the impossible burden that would be placed on generic manufacturers if accurate measures of therapeutic efficacy (in other words, clinical trial data) were required of all drugs, the PAC submitted instead that all drug manufacturers, in addition to providing evidence of chemical equivalence and purity already required by the FDA, should also adduce evidence of physiological availability "as judged by tests of disintegration, dispersion, and dissolution rates in appropriate solvents." And "in every case in which there may be doubt of biological equivalence ... biological tests should be required." ${ }^{35}$ In other words, the PAC argued that the FDA should require a modified NDA for all generic drugs, which should include proof that a generic drug was biologicallyand not just chemically-similar to the its brand-name equivalent. Until the FDA's evaluation of generic drugs was made more rigorous, the PAC opposed any legislation that mandated generic prescribing. The DES's findings thus stood in contrast to the recommendations of the Task Force on Prescription Drugs. ${ }^{36}$

That the two advisory bodies drew different conclusions reflected the divergent interests with which each group approached the issue of equivalence. The leading academic physicians who constituted the DES were primarily concerned with fulfilling the FDA's mandate of evaluating the

33. Alfred Gilman, "Therapeutic Equivalence of Generic Drugs and Problems of Drug Formulation," appendix A, minutes, Policy Advisory Committee of the Drug Efficacy Study, no. 3, March 27, 1968, NAS Archives, series 3 DES PAC 1968, Meetings folder, 27 Mar third.

34. William B. Castle, E. B. Astwood, Maxwell Finland, and Chester S. Keefer, "White Paper on the Therapeutic Equivalence of Chemically Equivalent Drugs. Prepared by a Subcommittee of the Policy Advisory Committee, Drug Efficacy Study," J. Amer. Med. Assoc. 208, no. 7 (1969): 1171-72, quotation on 1171. The views of the subcommittee reflected those of the broader Policy Advisory Committee.

35. Ibid, 1172.

36. Dominique A. Tobbell, "Allied against Reform: Pharmaceutical Industry-Academic Physician Relations in the United States, 1945-1970," Bull. Hist. Med. 82, no. 4 (2008): 878-912. 
efficacy of drugs marketed before 1962. In doing so they debated what should qualify as "substantial evidence" of efficacy, balancing pharmacological knowledge and incomplete or inadequate clinical data available on the marketed drugs with their own clinical experience of specific drugs. As the DES members made their evaluations they saw it as their task to create new scientific (and thus, ideally, objective) standards of efficacy that would eliminate subjectivity from the review process and guide future drug evaluations. In contrast, the government officials who made up the Task Force on Prescription Drugs had little interest in or expertise with which to debate the nuances of regulatory science. The Task Force's priority instead was to assess the cost-effectiveness of competing drug products that had already received FDA approval. Their primary calculus thus was of economics, not of pharmaceutical science.

The work of a third advisory body contributed equally conflicting perspectives to the debate over therapeutic equivalence. Following publication of the Task Force's report, the secretary of Health, Education and Welfare (HEW) appointed a committee, led by Harvard political economist John Dunlop, to review its findings and recommendations. The socalled Dunlop Committee was composed of nongovernmental officials drawn from a variety of backgrounds including physicians, academic and industry researchers, lawyers, and pharmacists. One of its priorities was to evaluate the issues of chemical, biological, and clinical equivalency in relation to current and proposed federal regulation, including the proposed Medicare drug benefit.

At the conclusion of its review, the Dunlop Committee agreed that establishing the biological or therapeutic equivalency for generic drug products was important and would result in lower drug costs for the consumer. However, the individual members of the committee could not agree on whether current USP standards-and the FDA's regulatory practices-guaranteed the therapeutic equivalence of generic drugs. ${ }^{37}$ The attitudes of the review committee tended to align according to their institutional background. Those representing the generic drug industry and pharmacists - the beneficiaries of generics legislation-supported the Task Force's findings, while those representing brand-name manufacturers and the AMA believed the Task Force had understated the problem of therapeutic equivalence. Despite the lack of consensus, the committee officially recommended that the "Food and Drug Administration continue to develop Reference Standards for generic drugs to assure biological 
equivalency among drug products." ${ }^{38}$ Implicit within this recommendation was an acknowledgment that current drug standards, those established by the USP, were lacking and that the FDA and not the USP should revise those standards. In doing so, the committee introduced a new timbre to the therapeutic equivalence debate: who should be the agency or institution responsible for the setting of drug standards?

\section{A Moment in Pharmaceutical Time: The Bioavailability Conference of 1971}

In the wake of the DES and the FDA's subsequent implementation of its findings (known as the Drug Efficacy Study Implementation, DESI), academic pharmacists and pharmacologists along with government officials began to hold regular meetings to discuss standards creation and method formation for the twin problems of "therapeutic equivalence" and "physiological availability." In the regulatory lexicon the "equivalence" problem was increasingly linked to the problem of "bioavailability."

At a seminal Washington conference in 1971, the dynamics of uncertainty and conflict over turf were laid bare on the table. It was a juncture at which the standards of bioavailability had scarcely been developed; hence the conference was pivotal in American discourse because it came at a moment of uncertainty, a moment of multiple paths. The conference was held at the National Academy of Sciences but was organized by the FDA, particularly by Henry Simmons, director of the Bureau of Drugs. The most forceful voice at the conference was that of Gerhard Levy, pharmacy professor at the University of Buffalo and probably the dominant academic voice pointing to the invalidity of chemical equivalence and urinalysis in examining bioavailability. Levy proclaimed that "[b]ioavailability problems are, in essence, problems concerning clinical effectiveness." Referring to the DESI, Levy proclaimed that "the time has come to undertake a review of the bioavailability status of all those marketed drugs which have not been assessed previously in this regard. The drug efficacy study [DES] . . . can serve as a model for such a project; the Academy of Pharmaceutical Sciences may be the appropriate body to carry out this task." 39

38. Ibid., 9 .

39. G. Levy, "Bioavailability, Clinical Effectiveness, and the Public Interest," in Conference on Bioavailability of Drugs at the National Academy of Sciences, reprinted in Bioavailability of Drugs: Proceedings of the Conference on the Bioavailability of Drugs, ed. B. Brodie and W. M. Heller (Basel: S. Karger, 1972) (hereafter PCBD), pp. 29-39, quotation on 35. 
Levy had been an outspoken critic of the weakness and backward character of USP and NF standards. Yet he argued at the 1971 gathering that the voluntary character of America's standards-setting institutions was central to the success of the American health system. "We can proudly point to the fact that our official standards of drug quality, as represented by the USP and the National Formulary, are not the result of governmental edict but derive solely from the efforts and sense of the responsibility of the health professions. Only we in the U.S. can make this claim." ${ }^{\prime 0}$

Yet speakers after Levy worried about the voluntary character of standards that he otherwise praised. Standards would not be adopted widely in terms of method and practice, argued W. H. Barr of the University of Buffalo, until they were accompanied by an enforcement mechanism; "the past decade has provided us with sample evidence that formulation variables can greatly affect the bioavailability and thus the clinical efficacy of many important therapeutic agents. Numerous in vivo and in vitro methods have been developed to assess these affects. We have not yet successfully applied them, however, to develop effective bioavailability standards in the case of many drugs for which standards are clearly required." ${ }^{11}$ The problem was the voluntary character of these institutions.

What can be done, and what should be done now, is to adopt a policy of full disclosure whereby manufacturers are required to include an appropriate statement in their product literature if the bioavailability of their product has not been established... . The disclosure of the bioavailability status of a drug product will permit more rational drug and drug product selection for the benefit of the patient and will serve also as a powerful stimulus for the prompt acquisition of adequate bioavailability information where such information is at present not available. ${ }^{42}$

University of Kentucky pharmacologist J. T. Dolusio expressed the problem more clearly.

There are often official standards regulating the manufacture of drug products. Unfortunately, at present these standards are only adequate with respect to insuring chemical equivalence. They emphasize things such as the purity of the drug, stability in dosage form, assay versus labeled potency, tablet to tablet to unit variation, etc.

40. Ibid., 33.

41. W. H. Barr, "The Use of Physical and Animal Models to Assess Bioavailability," in PCBD, 55.

42. Levy, "Bioavailability" (n. 39), 39. See also G. Levy and E. Nelson, "USP and NF Standards, FDA Regulations and the Quality of Drugs," N.Y. State J. Med. 61 (1961): 23. 
At present, there are no enforced standards which will insure bioavailability. One thus encounters products on the market which indeed fulfill all requirements for chemical equivalence but which are potentially inefficient with respect to their therapeutic effect in the body. Only the ultimate development of proper standards will insure that drug products are equivalent in all respects. This is why we are here. ${ }^{43}$

A month later in Montreal, Levy and Barr joined with other academic, governmental, and industrial pharmacologists to assess the limitations of existing bioavailability standards and the implications for Canada's regulatory practices. ${ }^{44}$ The conference included presentations by researchers from the Canadian government's Health Protection Branch (HPB, formerly the FDD) documenting differences in bioavailability among chemically equivalent versions of hydrochlorothiazide and nitrofurantoin tablets. In response, Levy urged Canadian officials to incorporate "bioavailability testing of generically equivalent drug products and periodic retesting of the innovator's products" and clinicians to regularly monitor their patients' drug levels using bioavailability studies. Levy reasoned that through these clinical pharmacokinetic studies, drug products could "be evaluated under realistic conditions in the appropriate population and without exposing normal subjects to unnecessary risks" and without relying on inadequate in vitro tests to evaluate a drug's bioavailability. ${ }^{45}$ Ontario's deputy minister of health, Allen Dyer, rejected Levy's suggestion, noting that Ontario's Ministry of Health "very strongly feel, that pharmaceutically equivalent products are, unless there is evidence to the contrary . . . therapeutically interchangeable." Alarmed, Levy countered, "[t] hat puts us back just about 200 years in health care! You see, is it also true that in the absence of data to the contrary, all drugs should be considered safe and effective? How far do we go?" ${ }^{46}$ Heeding Levy's warning and those of others, and acknowledging the growing number of studies from the United States showing the limits of bioavailability among seemingly equivalent drug products, Canada's HPB began to accept as therapeutically equivalent generic drugs with 80 percent to 120 percent of the bioavailability of a

43. J. T. Dolusio (Department of Pharmacology, University of Kentucky), in PCBD, 153.

44. L. P. Chenier and G. Maner, "Perspectives in Bioavailability of Drugs. Therapeutic and Toxicological Significance,” Revue Canadienne de Biologie 32, supplement (1973): 1-182.

45. Gerhard Levy, "Future of Bioavailability Studies," Revue Canadienne de Biologie 32, supplement (1973): 171-76, quotation on 175.

46. Gerhard Levy, Allen Dyer, George H. Schneller, Denys Cook, and Alan H. Conney, "Discussion," Revue Canadienne de Biologie 32, supplement (1973): 177-82, quotations on 179-81. 
reference standard (usually the innovator brand product). Availability was still assessed largely through excretion tests, but Canada's early practices provided a partial model for emulation among American regulators and standard setters.

Yet by November 1973, the HPB had reevaluated its stance toward generic equivalence. A series of studies published in Canada, the United States, and Britain between 1971 and 1973 had made clear that for some drugs 80 percent bioavailability produced dangerously inadequate clinical effects in patients while for other drugs 120 percent bioavailability led patients to suffer serious drug toxicity. ${ }^{47}$ Abolishing the 80 percent ruling, the HPB stated the "decision as to the acceptable range of bioavailability should be made separately for each drug based on a knowledge of such factors as the dose-effect curve of the drug, the therapeutic range, the nature of dose-related toxicities and the therapeutic use of the drug." 48

Some of the most important studies influencing the Canadian government's ruling documented the inequivalence-and resulting clinical effects-of different commercial preparations of digoxin. In October 1971, Finnish researchers reported in the British medical journal, the Lancet, that two different commercial preparations of digoxin were absorbed in vivo at significantly different rates. Because digoxin toxicity was a welldocumented risk of digoxin therapy, the Finnish team proposed, "If the patient is well established on a given preparation, unnecessary changes may increase the hazards of digoxin therapy and should be avoided." 49 An editorial two months later repeated the caution, warning readers that "[c] hanges in source of the digoxin tablet without knowledge of the physician or patient may lead either to reduction in therapeutic efficacy or to risk of digitalis intoxication." The editorial went on to note the inadequacy of British Pharmacopoeia (BP) requirements for tablet disintegration (the existing measure of equivalence) and suggested that for drugs with low ratios of therapeutic dose to toxic dose (such as digoxin), "non-

47. E.g., D. C. Blair, R. W. Barnes, E. L. Wildner, and W. J. Murray, "Biological Availability of Oxytetracycline HCl Capsules," J. Amer. Med. Assoc. 215 (1971): 251-54; J. Lindenbaum, M. H. Mellow, M. O. Blackstone, and V. P. Butler, "Variation in Biologic Availability of Digoxin from Four Preparations," New Engl. J. Med. 285 (1971): 1344-47; and C. Macleod, H. Rabin, J. Ruedy, M. Caron, D. Zarowny, and R. O. Davies, "Comparative Bioavailability of Three Brands of Ampicillin," Can. Med. Assoc. J. 107, no. 3 (1972): 203-9.

48. J. Ruedy, R. O. Davies, J. Brodeur, N. A. Hinton, I. R. Innes, A. Nantel, and J. M. Parker, "Bioavailability: Report of the Special Advisory to the Health Protection Branch, DNH\&W," Can. Med. Assoc. J. 109 (1973): 920-22, quotation on 920-21.

49. Vesa Manninen, John Melin, and Gottfried Härtel, "Serum-digoxin Concentrations during Treatment with Different Preparations," Lancet 298, no. 7730 (1971): 934-35, quotation on 935 . 
equivalence of preparations should be assumed until the characteristics of absorption have been demonstrated." 50

After several studies confirmed the findings of the Finnish team, British clinical pharmacologists urged the BP to revise its standards for equivalence. ${ }^{51}$ As D. G. Grahame-Smith of the Medical Research Council's Unit of Clinical Pharmacology, Oxford, and John Hamer of St. Bartholomew's Hospital, London, wrote,

Plainly the time has come to examine closely the procedures ensuring that preparations which can be dispensed as digoxin tablets B.P. have the same bioavailability. This is no academic point. Therapy with digitalis [digoxin] preparations is difficult enough, and the margin between therapeutic and toxic doses is small; likely therapeutic problems arise if the bioavailability of digoxin is too small... . We would suggest that the present standards, which, while ensuring that the amount of digoxin in the tablet is correct, do not ensure predictable bioavailability, are inadequate. We would strongly urge that this matter of the correlations between the method of pharmaceutical preparation, the physical properties of digoxin tablets, and the bioavailability of digoxin in man be fully investigated and new standards introduced. ${ }^{52}$

Britain's regulatory agency, the Medicines Commission, followed suit in September 1972 by requiring drug firms to submit bioavailability data in order to secure approval of new drug products. This did not appease the concerns of British pharmacologists. As the University of Sheffield's Robert N. Smith lamented, the commission "has not adopted the FDA's approach in commissioning comparative bioavailability studies on drugs, such as digoxin, which have been on the market for some years." Smith referred in particular to the work of the DES and the Task Force on Prescription Drugs. The problem, Smith continued, was that the British " $[\mathrm{g}]$ overnment would have to provide sufficient funds to support these studies and find suitably qualified units to perform them. Unlike North America there are few academic or hospital departments in Britain oriented to this type of work and with the necessary expertise in pharmacokinetics." Instead, the British government looked to the FDA for guidance on how to establish appropriate pharmaceutical standards. ${ }^{53}$

50. "Editorial: Biological Availability of Drugs," Lancet 299, no. 7741 (1972): 83.

51. Vesa Manninen, John Melin, and Pentti Reissel, "Tablet Disintegration: Possible Link with Biological Availability of Digoxin," Lancet 299, no. 7748 (1972): 490-91; T. R. D. Shaw, M. R. Howard, and John Hamer, "Variation in the Biological Availability of Digoxin," Lancet 300, no. 7772 (1972): 303-7.

52. John Hamer and D. G. Grahame-Smith, "Bioavailability of Digoxin," Lancet 300, no. 7772 (1972): 325 .

53. Robert N. Smith, "Generic Equivalence and Non-Equivalence of Drugs," Lancet 300, no. 7776 (1972): 528-30, quotation on 529. 


\section{The Discourse on Bioavailability: Regulatory Policy in Ambiguous Evolution}

The crucial linkage between bioequivalence and bioavailability was established in the late 1960s, less in discourse than in practice: the administrative evaluation of what were then termed "abbreviated new drug applications" (ANDAs). The ANDA process was established formally in regulations issued in February 1969 as a way for the FDA to deal with the DES findings. During the DES, numerous drugs were found to be "possibly effective" or "ineffective" for some of the claims listed in its labeling. In these cases, the FDA gave manufacturers two years to submit clinical data showing their drug's effectiveness for the stated claims. It was up to the manufacturers whether or not they did the clinical trials necessary to provide such data. Alternatively, the manufacturer could remove the ineffective ingredient from the drug, change the drug's label so as to omit the indication for which there was no evidence of effectiveness, or challenge the FDA's ruling in a hearing. In order to speed up the review process by which manufacturers could submit additional clinical data on their drug, rather than require the manufacturer to submit an entirely new and complete NDA, the FDA introduced the ANDA. At the core of the standards for ANDA approval was a demonstration not only of chemical equivalence but also of biological equivalence, and hence "biological availability."

Marion Finkel, deputy director of the Bureau of Drugs, addressed the trade association of (non-brand-name) generic manufacturers, the National Association of Pharmaceutical Manufacturers, on February 4, 1971. She offered a general message of assurance to drug makers who were deeply concerned that bioavailability requirements would necessitate wholesale clinical trials for their products. "If there is no methodology for determining bioavailability of certain agents, and if the FDA feels that the sponsor cannot develop 'adequate methods within a reasonable time,' the agency will opt either for clinical trials or dissolution tests. How it decides will vary with the seriousness of the disease to be treated and the need to assure therapeutic availability of the drug." ${ }^{55}$

Yet in crucial ways, Finkel and her colleagues intended to place a new burden of proof (and of labor) upon the generic manufacturers. "It will be the responsibility of the company to adequately ascertain from the

54. Federal Register 34 (February 27, 1969): 2673; Jerome Philip Skelly, "A History of Biopharmaceutics in the Food and Drug Administration 1968-1993," AAPS J. 12, no. 1 (March 2010): 44-50.

55. "FDA: Bio-Data Is OK Substitute for Clinical Trials on Some Drugs," Drug Trade News, February 22, 1971, 51. On Finkel's FDA career, see Carpenter, Reputation and Power (n. 4), chap. 5 . 
literature and appropriate consultants whether a bioavailability method exists or is feasible to develop." Finkel's argument was that an ANDA must employ a tablet disintegration test at the very least, yet her rhetoric pointed clearly to supplementary examinations, including the desirability of plasma studies. "The tablet disintegration test has been a useful regulatory criterion. However, it possesses only limited value for predicting the comparative bioavailability of two purportedly similar dosage forms." 56 Finkel advised manufacturers to check with FDA before undertaking any bioavailability tests (blood levels, urinary excretion, pharmacologic and metabolic assays). After consultation with internal experts or outside consultants, "FDA will either give a go-ahead or ask for modifications." Given the eight-year experience with the three-phase system of clinical development under the vast IND system, Finkel's pronouncement, along with the 1969 rules, implied some regulation and veto control over phase I and animal studies. In that three-phase system, phase I corresponded to the first human experiments to determine toxicity and dosage, phase II covered initial trials of a limited number of patients for specific disease control, and phase III corresponded to a full-scale randomized controlled clinical trial to assess drug safety and efficacy. ${ }^{57}$

In administrative practice, FDA reviewing divisions were already demanding the same sort of data specificity that they would require of a NDA for a new molecular entity. In its evaluation of NDA 16-815 (hydrochlorothiazide tablets, manufactured by Zenith Laboratories in Hoboken, N.J.), the FDA required the submission of data to establish bioavailability and bioequivalence (to the pioneer brand Hydrodiuril) for two dosage forms of hydrochlorothiazide tablets. These were submitted in lieu of clinical trials to support safety. In principle, FDA statistician Walter Sloboda would have accepted the submission for the purpose of review, but he declined to do so. His division was unable to "conduct a statistical evaluation" of Zenith's data because

a. No narrative or interpretation of the results of this study are given. No details are provided with reference to the study regimen, the design, nor the method by which treatments were allocated.

b. No explanation is given of the coding which is used for the computer printout sheets. No details are provided concerning the computer program which was used for the statistical analysis.

c. Copies of the original laboratory analyses are not included in the submission.

d. A number of pages have missing data. 
The upshot of these deficiencies was that "we are thus unable to determine what the submitted data mean or how to interpret this submission." To provide a hard incentive for Zenith Laboratories to meet these data standards, Sloboda recommended that his superiors refuse to meet with Zenith officials until the data were provided in a proper form..$^{58}$

By the time of the 1971 National Academy of Sciences conference on bioavailability, FDA commissioner Charles Edwards could speak authoritatively on the need for demonstration of bioavailability in any and all NDAs, including generic applications.

The time has passed when chemical equivalency can be considered the sole criterion of acceptability by a manufacturer for marketing a drug, the safety and efficacy of whose reference standard has previously been demonstrated in clinical trials. ... Biological availability data in lieu of clinical trials are, therefore, required for (1) all products suitable for abbreviated new drug applications, providing a methodology is feasible, and (2) for all revised formulations of previously approved drugs (which were originally found effective in clinical trials), again assuming methodology is feasible..$^{59}$

The upshot of these considerations was that demonstration of bioequivalence for an ANDA required demonstration of equivalence in availability at the target site.

Despite these changes in practice, changes in formal institutionsnamely the NDA and the administrative and experimental barriers that it created for market entry-were slow in coming. Generic drug makers still had to file a "paper NDA" in order to satisfy the requirements of the FDA approval process for molecular entities. This process demanded an administrative and structural liaison with the FDA that few generic manufacturers possessed, and it also required the completion of many clinical trials. As two patent attorneys who followed the development of legislation would later notice, the NDA process became a sort of stand-in for the patent protection lost by brand-name manufacturers due to lags in FDA review of the original molecular entity. ${ }^{60}$

58. Memorandum from Walter Sloboda to Heino Trees (Division of Cardiopulmonary and Renal Drug Products), September 18, 1970, DF 505.8 (AF 30-841), RG 88, National Archives.

59. Edwards, "Welcome Address" to Conference on Bioavailability of Drugs at the National Academy of Sciences, reprinted in PCBD, 12.

60. Fox and Bennett, Legislative History (n. 2), iii. On the lengthening of new drug approval times see, Carpenter, Reputation and Power (n. 4), chap. 3. 


\section{The Return of Legislative Politics}

The organizational battle between the USP and the FDA was in full force, but the critical audience-the U.S. Congress-was increasingly convinced that USP standards were not sufficiently enforceable or stringent. In 1973, as the Senate Subcommittee on Health chaired by Edward Kennedy began new hearings on the pharmaceutical industry, the issue of generic drug equivalence standards - and their regulatory ramifications - was prominent.

On the opening day of the Kennedy hearings, HEW secretary Caspar Weinberger introduced the department's proposal to limit reimbursement for drug purchases under federal programs, including Medicare and Medicaid, to "the lowest price at which the drug is generally available, unless there is demonstrated difference in the therapeutic effect." ${ }^{61}$ Despite the problems identified by the Dunlop Committee and DES, the so-called Maximum Allowable Cost (MAC) program was predicated on the assumption that "uniform quality and therapeutic equivalence of drugs can be and is being assured." ${ }^{2}$ The PMA opposed the HEW policy on the grounds that "medically and scientifically, there is a uniform opinion that equivalency cannot be assumed today, and that is exactly what Weinberger's proposal is bottomed on." ${ }^{63}$ Despite the incorporation of bioequivalence into ANDAs, PMA president Joseph Stetler contended the FDA was in no position to guarantee the quality or effectiveness of different versions of the same drug. He warned that rather than being closer to a solution on the issue of equivalence, reports of the therapeutic inequivalence of generic drugs were increasing. As evidence, Stetler cited the Department of Defense's rejection of 42 percent of drug samples submitted to it-the majority of which had been approved by the FDA-because they failed to meet the department's own quality control standards. Included within the department's quality assurance standards was detailed proof of a drug's therapeutic equivalence as determined by laboratory tests, animal studies, and clinical trial data. ${ }^{64}$ Stetler blamed the failures in "quality control" on the FDA, noting that FDA inspections of drug plants had been decreasing in frequency. While the 1962 Drug Amendments required the FDA

61. FDC Reports, December 19, 1973, pp. A1-A7, quotation on A6.

62. "Statement of C. Joseph Stetler," Examination of the Pharmaceutical Industry, 1973-1974. Hearings before the Subcommittee on Health, Committee on Labor and Public Welfare, U.S. Senate, 93rd Congress, 1st and 2nd Sessions (hereafter the Kennedy Hearings), December 19, 1973, 336-63, quotation on 336.

63. Ibid., 337.

64. "Clinical Equivalency Proof for Military Drug Purchase," FDC Reports, May 1, 1967; Max Feinberg, "How We Seek Quality in Competitive Drug Procurement," Pharmacy Times, December 1973, 36-41. 
to inspect drug manufacturers at least every two years, Stetler argued that some drug manufacturers had not been inspected for five years, while others had never been inspected..$^{65}$

Despite their economic stake in the outcome of the hearings, generic manufacturers were conspicuously absent during the Kennedy hearings and the political and legislative debates that followed. Constrained by a lack of resources and by the nebulous character of the generic drug industry, the trade association of small generic firms, the National Association of Pharmaceutical Manufacturers, held no political power. Support for the MAC program was left instead to nascent consumer and patient advocacy groups such as Ralph Nader's Public Citizen, state and municipal health agencies seeking to reduce their health care costs, and the American Pharmaceutical Association, which represented a core segment of organized pharmacy (notably, however, all other pharmacy groups joined with organized medicine and brand manufacturers in opposing the MAC program).

In stark contrast to the generic manufacturers, brand-name manufacturers were, by the early 1970 s, a well-organized and politically unified industry possessing an extensive public relations and political affairs machinery. Since the mid-1950s, the industry-represented by the NPC and PMA — had organized a series of political and public relations campaigns against pharmaceutical reform legislation, including that of generic substitution and mandatory generic prescribing. The NPC's antisubstitution campaign of the 1950s, for example, had resulted in forty-four states passing antisubstitution legislation by the end of that decade (banning pharmacists from dispensing a generic drug in place of a prescribed brand-name drug) ${ }^{66}$ More recently, the press had accused the PMA of pressuring the White House to withdraw its support for the appointment of a staunch advocate of generic prescribing to the position of director of the FDA's Bureau of Medicine ${ }^{67}$ At the end of the 1970s, the National Association of Pharmaceutical Manufacturers accused brand-name manufacturers of "successfully using scare tactics to keep doctors prescribing, pharmacists dispensing, and patients requesting the more expensive brand-name drugs when there are cheaper generic versions available." ${ }^{\prime 8}$

65. "Statement of C. Joseph Stetler" (n. 62), 337.

66. See Tobbell, "Pharmaceutical Networks" (n. 13), esp. 96-134; Tobbell, "Who's Winning?" (n. 6); and Tobbell, "Allied against Reform" (n. 36).

67. E. W. Kenworthy, "Doctor Suggests Drug Men Denied Him Post in FDA," New York Times, August 26, 1969, 1.

68. Gina B. Kolata, "Large Drug Firms Fight Generic Substitution," Science 206 (November 30, 1979): 1054-56, quotation on 1054 . 
During the congressional debate over the MAC program, Stetler blamed the FDA's failings on a shortage of labor and resources, while Secretary Weinberger and FDA officials denied such charges and maintained the FDA was able to ensure the equivalence of generic drugs. Stetler's arguments against the MAC policy represent a deft political maneuver by the PMA. Whereas the industry's political strategy in the 1960s had been to criticize the lack of generic drug regulation (i.e., that no bioequivalence or clinical equivalence data were required by the FDA for generic approval), in the early 1970s that strategy had shifted to casting doubt on the ability of the FDA-which was now evaluating bioequivalence-to fulfill its regulatory responsibilities, a central feature of the "drug lag" debates that dominated pharmaceutical politics throughout the $1970 \mathrm{~s} .{ }^{69}$

Just as they had during the Nelson hearings, the industry's arguments stemmed from legitimate scientific and regulatory concerns. In the hopes of resolving the lingering uncertainty about generic drug equivalence standards, Kennedy referred the matter to the Office of Technology Assessment (OTA). The Drug Bioequivalence Study Panel of the OTA, chaired by Robert Berliner, dean of Yale's School of Medicine, and composed of several leading academic physicians and pharmacists, was charged with addressing whether the FDA could "guarantee bioequivalence of multisource drug products under the present regulations."70

In July 1974, the Berliner Committee concluded, "present compendia standards and guidelines for Good Manufacturing Practice do not insure [sic] quality in uniform bioavailability for drug products." As such, "current standards and regulatory practices do not insure [ sic $]$ bioequivalence for drug products." 71 The system of standards setting was, in essence, broken. The culprit, the committee contended, was the voluntary nature of the system and the resulting lack of resources available to the institutions charged with developing and revising drug standards, the USP and NF. The committee argued that the "continued reliance" of these institu-

69. In the early 1970s, clinical pharmacologists Louis Lasagna and William Wardell argued that as a direct result of the 1962 Drug Amendments the U.S. pharmaceutical industry had made significantly fewer pharmaceutical innovations and as a result the public's health was suffering. Louis Lasagna and William M. Wardell, Regulation and Drug Development (Washington, D.C.: American Enterprise Institute for Public Policy Research, 1975). See also Arthur A. Daemmrich, "Invisible Monuments and the Costs of Pharmaceutical Regulation: Twenty-Five Years of Drug Lag Debate," Pharm. Hist. 45 (2003): 3-17.

70. Senator Edward Kennedy, Opening Statement, Brand Names and Generic Drugs, 1974. Kennedy Hearings, July 22, 1974, 1.

71. Drug Bioequivalence Study Panel, U.S. Office of Technology Assessment, "Drug Bioequivalence" (Washington, D.C.: Office of Technology Assessment, 1974), 1-78, quotations on 1, 2. (Online copy at http://www.fas.org/ota/reports/7401.pdf.) 
tions "upon such limited resources is anachronistic and inadequate for the scientific activities necessary to insure pharmaceutical equivalence of drug products." ${ }^{" 2}$ Essential to fixing the system was, the committee argued, the establishment of "a single organization," federally funded, "to supersede the USP and NF as the official standard-setting organization of the Federal Government." " Although reluctant to recommend a specific organizational location for the new standards-setting body, the committee suggested the FDA might assume responsibility for the setting of drug standards, as long as the standards-setting group remained separate from the agency's compliance-monitoring group. ${ }^{74}$

The upgrading of drugs standards and the feasibility of HEW's MAC program, however, required more than just organizational change. As with the earlier advisory bodies, the Berliner Committee concluded that it was "neither feasible nor desirable that studies of bioavailability be conducted for all drugs or drug products. ${ }^{75}$ By identifying only those drugs for which bioavailability studies were critical, the setting of generic drug equivalent standards could be rationalized. In particular, the committee reasoned, drugs with a narrow margin between therapeutic dose and toxicity "would be candidates for testing of bioavailability, since relatively modest changes in the concentration achieved in body fluids might well be associated with large changes in the frequency of therapeutic failure or significant toxicity." ${ }^{~}{ }^{6}$ Such drugs included digoxin, corticosteroids, and certain antibiotics such as chloramphenicol. In contrast, for any drug for which there was a large margin between its effective concentration and its toxic level, such as penicillin, " $[\mathrm{m}]$ oderate differences in the concentration achieved in the blood owing to differences in bioavailability ... would be easily tolerated." ${ }^{77}$ In other words, two classes of drugs should be distinguished: those for which evidence of bioequivalence is not considered essential and those for which evidence of bioequivalence (and thus bioavailability data) is critical. In the case of the latter, bioequivalence requirements should become a feature of a drug's dose-response curve or toxicological profile.

Based on this two-class distinction, the committee recommended the establishment of an official list of interchangeable drug products. Those drugs for which evidence of bioequivalence was not considered essential could be added to the list as soon as chemical equivalence had been dem-

72. Ibid., 32.

73. Ibid., 53 .

74. Ibid., 51-54.

75. Ibid., 22.

76. Ibid., 23.

77. Ibid., 22-23. 
onstrated. Those drugs for which evidence of bioequivalence (and thus bioavailability data) was deemed critical could be listed only after bioavailability data had been provided and approved. ${ }^{78}$ At the policy level, the MAC program would apply to only those drugs listed as interchangeable.

Neither the Berliner Committee's report nor the Kennedy hearings brought complete closure to the issue of bioequivalence. Although the MAC program was officially announced in 1975, the first MAC programs - for penicillin and ampicillin-did not become effective until June 1977, and subsequent MAC programs were introduced only slowly and sporadically, as and when the FDA was able to guarantee the therapeutic equivalence of participating drugs. Yet by late 1974, numerous observers had concluded that the FDA had taken over standard setting in matters of availability. In revising their classic textbook The Pharmacological Basis of Therapeutics, Louis Goodman and Alfred G. Gilman, Jr. (son of the Nobel laureate) noted that the FDA had displaced the USP. As Goodman reminded the young Gilman in correspondence over revisions on New Year's Eve in 1974, “The bioavailability (plasma conc.) area is pre-empted by FDA, not USP, for the present." 79

The plasma concentration discussion was also furthered by developments in pharmacokinetics that used simulation and analytic techniques to assess the area under the time-concentration curve (AUC). The AUC was calculated by estimating the time-concentration curve (much like the one depicted in Lloyd Miller's notes on tolbutamide in Figure 1), and pharmacokineticists used different techniques for integrating the "mass" under that curve. The methods for performing these calculations were readily available from pharmacokinetics and pharmacodynamics in the 1960s and 1970s, and they relied upon features of linear mathematics that rendered serum-based tests relatively easy to apply and interpret statistically and clinically. ${ }^{80}$ Applying the concept of linearity to pharmacokinetics, pharmacologists assumed that although variations in dosage, inactive ingredients, and form of drug administration could affect the absorption of a drug's active ingredient into the blood and thus affect its bioavailability, those same differences in dosage, inactive ingredients, and administration would not affect the way by which availability in the

78. Ibid., 55.

79. Goodman to Alfred G. Gilman, Jr., December 31, 1974, "No info available re a 1975 European Pharmacopoeia. The bioavailability (plasma conc.) area is pre-empted by FDA, not USP, for the present," Louis Goodman Papers, Alfred G. Gilman folder, Marriott University Library, University of Utah, Salt Lake City.

80. Sharon Anderson and Walter W. Hauck, "Consideration of Individual Bioequivalence," J. Pharmacokinetics Pharmacodynamics 18, no. 3 (June 1990): 259-73, esp. 260, 268. 
blood translated into availability to drug targets. In this rendering, bioavailability data (calculated from serum-based tests) would correspond to bioequivalence at the drug target site. ${ }^{81}$

\section{The Codification of an Administrative Vocabulary: Hatch-Waxman and the Modern Generic Drug System}

The critical regulation making occurred in the late 1970s with three officials in the lead-J. Richard Crout (director of the Bureau of Drugs), hematology specialist Bernard Cabana, and FDA physician John Harter. Crout's Bureau of Drugs was arguably the most powerful middle-level organization within the FDA, and the Bureau of Drugs had its own rulewriting team. Cabana was a critical force in the development of the rules. He was director of the Division of Biopharmaceutics, and his training at SUNY-Buffalo (with Gerhard Levy and W. H. Barr) and his previous experience at Bristol Laboratories had given him an excellent and legitimized professional perch from which to orchestrate the marriage of bioavailability and bioequivalence. ${ }^{82}$

The wedding of bioavailability to bioequivalence became formal in a series of FDA rules issued and published in the Federal Register from 1973 to $1977 .{ }^{83}$ As with an amended NDA process, the series of critical court victories won by the FDA was absolutely essential in empowering the agency with the legal authority and the regulatory moxie to issue these broad and far-reaching standards. The Hynson decision and others from the federal courts basically established the authority of FDA to set experimental standards and apply them without full administrative hearings in each case where applied.$^{84}$ Crout, Cabana, and Harter's efforts became official with the publication of the first "Orange Book" listing therapeutically equivalent products in January 1979 (see Figure 2). The Orange Book was in formality a "proposal"-a setting forth of provisional rules in the Federal Register — but very little about the rules would change from proposed to final form. Perhaps most centrally, the January 1979 proposal

81. Victor Smolen, "Bioavailability and Pharmacokinetic Analysis of Drug Responding Systems," Annu. Rev. Pharmacol. Toxicol. 18 (1978): 495-522.

82. Skelly, "History of Biopharmaceutics" (n. 54), 47.

83. Federal Register 38 (January 22, 1974): 885; Federal Register 40 (June 20, 1975): 26164; Federal Register 42 (January 7, 1977): 1624; Federal Register 42 (August 23, 1977): 4231.

84. Robert Spencer, "Bioequivalence/Bioavailability—The FDA's Plans," Food, Drug Cosmetic Law J. 31 (1976): 32-38; Bernard Cabana, "Bioavailability/Bioequivalence," Food, Drug Cosmetic Law J. 32 (1977): 512-26; James T. Dolusio, "A Definition of Bioequivalence/ Bioavailability and a Historical Perspective," Food, Drug Cosmetic Law J. 32 (1977): 506-11. 


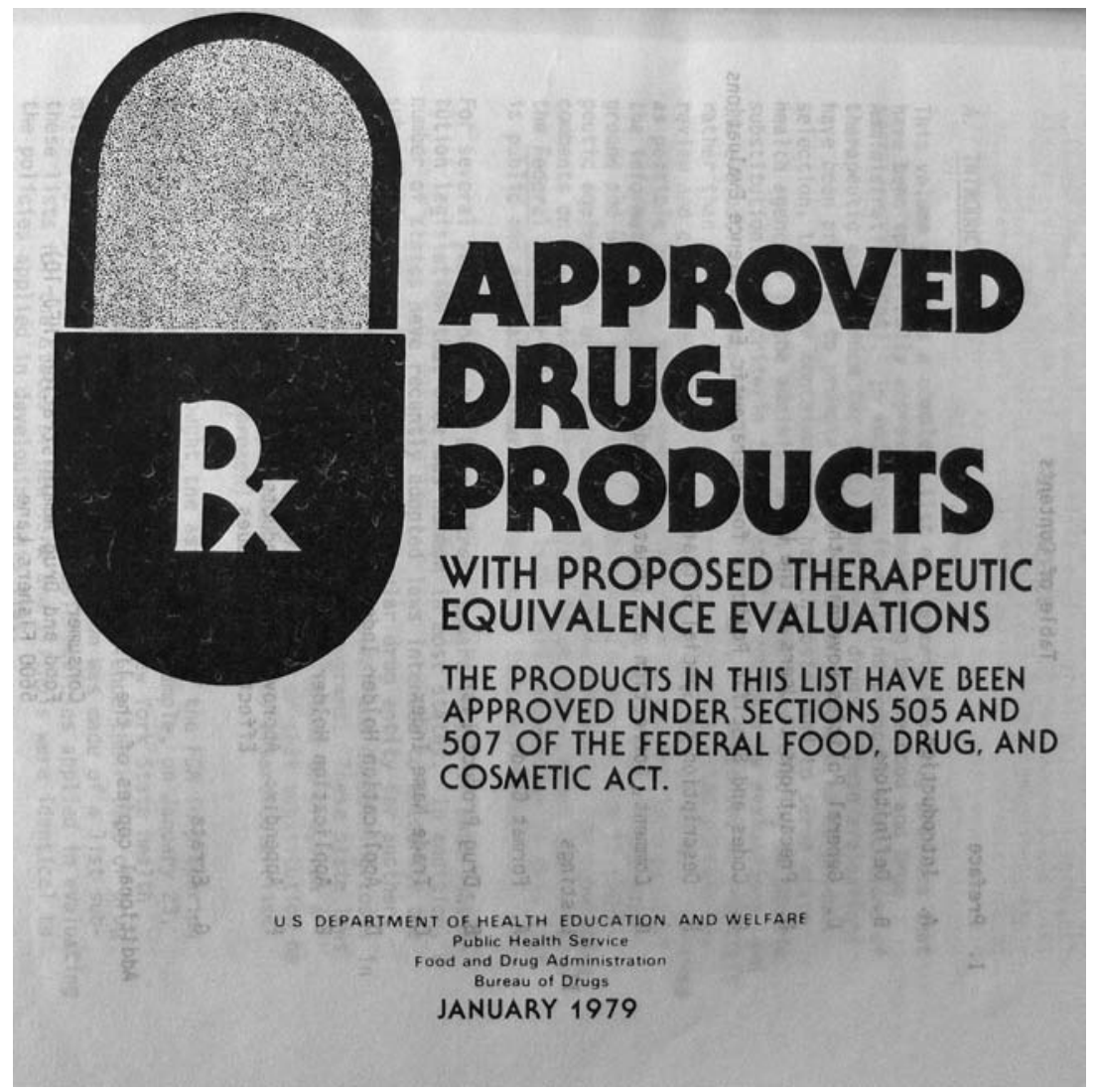

Figure 2. Origins of the "Orange Book": FDA Bureau of Drugs's Proposed Bioequivalence Regulations and Listings, January 1979.

included model legislation for generic substitution in state Medicaid formularies, legislation that was drafted between Crout's team and the Federal Trade Commission. The role of regulation in standardizing not merely scientific concepts but also policy proposals has been little narrated from this period.

The rule making of Crout, Cabana, and Harter accomplished much more than the solidification of regulatory practices. It also eased the path of legislation several years later. In two ways, the Bureau of Drugs's rule making changed the policy making game. First, the Bureau of Drugs had solidified concepts and procedures, and by so doing, its rules reduced legislators' and bargaining parties' uncertainty. It would, in the 1980s, be much easier for all parties to strike a feasible trade-off once the basic concepts 
had been pinned down. Evidence of this comes in the minimal legislative revision of the Hatch-Waxman provisions in Congress. Second, the threat of rule making brought the political representatives of the American pharmaceutical industry more eagerly to the table. In the absence of steady rule making development, the organized pharmaceutical industry was happy to witness a fallback to the status quo, wherein generic manufacturers would have to file a "paper NDA" that required either new clinical trials or published trials that demonstrated the efficacy of its product. As the FDA began to create a generic drug approval process on its own, however, the fallback option became not the paper NDA but whatever the FDA's Bureau of Drugs would create as an administrative system.

Bioequivalence standards effected through rule making, then, provided not only a conceptual framework but a political incentive for HatchWaxman's enactment. With the FDA's rule making for a generic drug approval process proceeding apace in the late 1970s, the brand-name manufacturers were caught in a bind. The bald choice was to resist the rule making with uncertain prospects for legislative or legal victory or strike a deal to accept a generic drug approval process in statute while getting something out of the bargain. As a former PMA president noted, brand-name manufacturers chose the latter.

For those who ask whether Hatch-Waxman was a good deal or a bad deal for the research-based pharmaceutical industry, the most learned response is: It was not a good deal, unless one believed that FDA was going to go forward with its plans to implement abbreviated new drug applications (ANDAs) through regulation. If one thought that was going to happen-and FDA was working on it-then Hatch-Waxman probably was a good balance. If one did not think that would ever happen, Hatch-Waxman probably was not a good balance, at least at the time. ${ }^{85}$

The Hatch-Waxman legislation experienced many changes in the House and Senate, and as well in the conference committee. But the provisions relating to bioequivalence, bioavailability, and ANDAs were largely unchanged from the original measure. They were also little altered from the FDA regulations issued in January $1979 .{ }^{86}$

The deal that had so long eluded members of Congress on generic drugs was able to be struck because the concepts were in place for a legislative bargain. Indeed, the legislation limited the FDA's discretion in one important sense, namely that the agency could impose no more stringent or less stringent requirements than were contained in the ANDA

85. Mossinghoff, "Overview" (n. 2), 187.

86. Fox and Bennett, Legislative History (n. 2), 2, 213. 
regulations. Hence both generic and brand-name manufacturers could regard the FDA's ANDA regulations as the final and stable word on what a generic drug pathway to market would look like. Once in place, the American nexus between equivalence and availability began to spread to other countries and international institutions. This development occurred in complicated ways, at cross-cultural and cross-institutional interfaces, and merits a separate study. ${ }^{87}$

The Hatch-Waxman Act offered generic and brand-name manufacturers more than side payments in a larger legislative bargain. It also offered stability in regulation and a template of predictability for the future. For brand-name manufacturers, the act offered the certainty of patent extension; for generic manufacturers, a path to the market was clear. And for both sides, the act reduced uncertainty over policy developments by codifying present procedures and ensuring that future rule making would be unlikely to depart from the Hatch-Waxman compromise, at least for a while. Brand-name companies could rest assured that no change in personnel or thinking at the FDA would permit generic drugs to come onto the market more cheaply or with less testing than under the ANDA procedure. For generic companies in particular, the act reduced uncertainty by reining in the FDA's discretion to alter testing requirements for generic drugs. Title I of Hatch-Waxman textually authorizes ANDAs and prohibits the FDA from doing anything beyond asking for bioavailability studies. ${ }^{88}$

Blood serum bioavailability still comprises the dominant criterion of comparability for generic and pioneer drugs among small-molecule pharmaceuticals. From 1982 to 1992, the FDA operated under a set of rules, perhaps the most prominent known as the $75 / 75$ rule, which stipulated that similarity required at least 75 percent of subjects in an equivalence study to have bioavailability within at least 75 percent of the pioneer standard. The rule thus relied heavily upon "within-subject" variability and examined not only the average availability of the generic formulation but also its variance over a sample. ${ }^{89}$ The other common rule of the time, and which superseded the $75 / 75$ rule on the basis of its perceived statistical

87. Ibid., 23; Roger L. Nation and Lloyd N. Sansom, "Bioequivalence Requirements for Generic Products," Pharmacol. Therap. 62 (1994): 41-55. On the spread of other FDAoriginated concepts and regulations around the modern pharmaceutical world, including twentieth-century India and its regulation of Ayurvedic medicines, see Carpenter, Reputation and Power (n. 4), chap. 11.

88. Mossinghoff, "Overview" (n. 2), 189.

89. Anderson and Hauck, "Consideration of Individual Bioequivalence" (n. 80), 266-67; Bernard E. Cabana, "Assessment of 75/75 Rule: FDA Viewpoint,” J. Pharmaceut. Sci. 72 (1983): 98-99. 
superiority, is the $80 / 20$ rule, which is also called the "plus-or-minus 20 percent test." This standard requires that the amount of active ingredient in the patient's blood over a specified time interval must lie within 20 percent, positive or negative, of the level observed with the pioneer version of the molecule. As one recent commentator suggests, the homogeneity of the FDA's standards is open to question. Other "therapeutic bands" are possible, as "many medical professionals believe that for drugs that have a wide index of tolerance, twenty percent is not important at all, in such instances, twice as much or half as much of the active ingredient in a generic product will still work. ${ }^{.90}$ More narrow therapeutic bands may be appropriate for antiseizure medication or other indications where less variability is appropriate. Perhaps one indication of the breadth and stasis of the FDA's standards is that, at this writing, they still engender complaint. Laments about the heterogeneity of availability and the ways that particular drug classes elude federal standards flow not only within academic networks but also in public arenas. A widely read article in the New York Times in December 2009—titled "Patient Money: Not All Drugs Are the Same After All"-questioned the uniformity of standards applied to molecular therapies in the American health system. ${ }^{91}$

Whichever standard is used, the FDA's standards of the late 1970s and early 1980s have become the starting point for scientific discussions and industry lobbying. Their status as target for scientific, industry, and medical criticism only confirms their centrality, their existence as default criteria. FDA officials were, as we have shown, not the sole authors of these rules, and the conceptual and methodological architecture of bioequivalence has been shaped by academic pharmacologists, by drug companies worried about the availability of their own preparations, and by the criticisms of consumer groups. The determination of equivalence as published in the Orange Book has become a target and a platform for pharmaceutical lobbying. Large pharmacy chains such as CVS Caremark routinely press the FDA for clearance of ANDAs—-pointing to therapeutic equivalence determinations as the basis for their claims-in part because the availability of generics will increase total volume and will benefit total

90. The $80 / 20$ standard owed much to Canadian regulatory writings (see discussion on p. 115). It is likely, however, that the widespread acceptance of this standard in the global pharmaceutical world was facilitated by the FDA's 1978 rules and the 1984 statute as well as the work of the FDA statistician. See Mossinghoff, "Overview" (n. 2), 190.

91. Leslie Alderman, "Patient Money: Not All Drugs Are the Same After All," New York Times, December 18, 2009, http://www.nytimes.com/2009/12/19/health/19patient. html?ref=health (accessed December 23, 2009). 
pharmacy sales. ${ }^{92}$ And bioavailability standards measured and enforced through blood serum testing have become central to FDA decisions for NDAs for pioneer molecules as well, often in discussions over labeling where patient compliance is at issue. ${ }^{93}$

The USP and other organizations have not, to be sure, waned from relevance or visibility in the global pharmaceutical realm. The USP still maintains primary authorship over chemical purity, strength, and equivalence standards (though these are largely enforced by the FDA and global medicines regulators through inspections, quality control regulations, and GMPs). However, the centrality of plasma analysis in bioequivalence implies that generic equivalence has largely become an issue tackled primarily by the FDA and other global medicines regulators who have transcended chemical analysis to orchestrate a blood-based methodology and discourse of availability and equivalence of medicines.

As the nation and the world confront issues of comparative effectiveness of drugs as well as biosimilarity for biopharmaceuticals, the narrative of bioequivalence provides guidance for our collective dialogue. Regulatory arenas often provide sites for conceptual innovation as well as standardization.

DANIEL CARPENTER is Allie S. Freed Professor of Government at Harvard University. He is the author, most recently, of Reputation and Power: Organizational Image and Pharmaceutical Regulation at the FDA (Princeton University Press, 2010).

DOMINIQUE A. TOBBELL is assistant professor in the program in the History of Medicine at the University of Minnesota-Twin Cities campus. She is the author of Pills, Power, and Policy: The Struggle for Drug Reform in Cold War America and Its Consequences (Milbank Series on Health and the Public, University of California Press, 2012).

92. Wayne H. Maleski (counsel to CVS Caremark), Arent Fox LLP, to FDA, division of Dockets Management, October 19, 2007, Re FDA docket number 2007N-0382, "Comments Regarding 180-Day Generic Drug Exclusivity for Ramipril Capsules," docket number 2007N-0382, FDA.

93. In the middle 1990s, the FDA's drug reviewing divisions considered issues of bioavailability for Merck's Fosamax (alendronate) for Paget's disease. Here the comparison was not between a pioneer and a generic molecule but between two pioneer molecules, namely alendronate and etidronate (Didronel, manufactured by Procter \& Gamble). "Fosamax is Effective in Paget's Regardless of Disease Severity and Previous Piphosphonate Treatment; Shows Greater Efficacy Than Etidronate," F-D-C Reports, Pharmaceutical Approvals Monthly, July 1996, 27. 